\title{
Vernal keratoconjunctivitis
}

INSERM

\section{Source}

INSERM. (1999). Orphanet: an online rare disease and orphan drug data base. Vernal keratoconjunctivitis. ORPHA:70476

Vernal keratoconjunctivitis is a chronic (seasonal) allergic inflammation affecting the conjunctiva and cornea of the eye. It is most common in young boys and is characterised by red eyes, photophobia, itching and excessive tearing. It generally improves during adolescence. 